\title{
The Impact of Parental Enforcement, Societal Demands and Text Books Role on Students' Interest towards the subject of Chemistry
}

\author{
Tayyaba Muhammad Akram ${ }^{1}$, Aisha Sami ${ }^{1}$, Anam Ilyas ${ }^{1}$, Hamid Ikram ${ }^{2}$ \\ ${ }^{1}$ University of the Punjab, Lahore, ${ }^{2}$ Government College University, Faisalabad, Pakistan
}

\begin{abstract}
Personality is an important feature in development of students' attitude towards Chemistry. The basic aim of this research was to explore the relationship among personality traits and students' attitude towards the course of Chemistry. Results found in this research work also determine the effect of gender and class on students' personality along with affective traits of attitude. The sample size was consisting of 780 secondary school (male and female) students. Valid and reliable instrument was developed. Data was analyzed through correlation and t-test. It is concluded that there is considerable mean effect of demographic variables on students' personality and attitude. Whereas $t$-test revealed that gender (male and female students) as well as class (9th and 10th grade students) showed significant difference in affective characteristics of attitude and effect of personality traits towards the chemistry course. Results and findings in this research paper is useful and significant for parents, teachers, curriculum developers and educators in order to reform, plan and design curriculum and teaching methodologies according to the requirement of the modern world.
\end{abstract}

\section{Introduction}

Interest is a major element in science education and science is considered as an interesting subject [1]. Interest in science get new life in science educational societies from last few years' [2], [1]. Previous researches claimed that trend of choosing science subjects declined in young [3]. It is evident from literature that students' interest getting declined towards the discipline of chemistry [4], [6], [7], [8], [9], [1], [10], [11], [12], [13]. Despite of the vital importance of chemistry, it is considered a complicated and depressive subject by students [7]. Number of scientists reduced all over the world along with it their unsatisfied performance of chemistry students represents an alarming situation [3].

The concept of interest belongs to the broad category "attitudes towards science" that is a group of affective variables, including interest in science is one of its element [3]. 21st century is predicted for rebuild students' interest in science particularly in chemistry. Likewise, the Pakistani curriculum documents also strongly emphasized to develop students' interest as ambition National Curriculum of Chemistry at IX-X Grades [5].

Numerous studies declared several factors responsible for declining the students' interest towards science subjects. These factors may include academic records, type of school, parental occupation, socio-economic status, prior learning experiences and curriculum [10]. These factors may vary from student to student but the differences are more visible among different countries [3].

In this study, factors such as; "Parental Enforcement", "Societal Demands" and "Text Books Role" that could be responsible for the altering the interest of Pakistani students are discussed.

\section{Parental enforcement}

Parents' cooperation, support, encouragement, and responsibilities significantly influenced on child's interest and good achievement in studies [14] [15]. PISA studies revealed that those students who live with their parents, show better achievement scores [15]. Parent occupation also participate on children success according to PISA findings [15]. Furthermore, outcomes of the study show that students attained significantly healthier scores whose parents are associate with managerial or professional occupations, compared to others [14], [15].

\subsection{Societal demands}

Chemistry learning associated with its implication for societal benefits [6]. In the opinion of researchers [10], youth detachment and dissatisfaction from the science create gaps between science and society. In result of this distances scientific and moral dilemmas arose such as green-house effect, global warming, variations in the genetic makeup of food items, confront society [10]. Investigators like Jong, [9] mentioned the plan for improving the curriculum of chemical education, from current society and other issues. Scientists [10] revealed their thoughts that scientific matters must be discussed in media. A 
view given by researcher [6], is that inside the school and its outer world chemistry learning must be linked and exercise in actual situation. Doctor Aikenhead defined that each sort of significance for school science is directed by different ideologies of education, science and society [4].

\subsection{Text books role}

Science curriculum connects students' interest and worldly experiences produce optimistic attitude in school science students [3]. Science students considered the chemistry course in both dimensions, easy as well as difficult [13]. Application of curriculum probably placed encouraging effect on student behaviors and beliefs for the importance of chemistry [6]. Researchers [12] discussed that there is indirect correlation exists between students' perception about the difficulty of a topic and their low academic achievement based on school category attending by them. Over loaded curriculum frustrates the students and before final evaluation, shortage of time for book revision, chemistry practical performance and science discussions troubled them [7], [10]. Insufficient laboratory apparatus's, don't allow students to perform individual practical work with confident [16]. Scholars examined to explore the details about linkage of daily life examples of chemistry due to its abstract nature [6], [12], [10], [16]. Previous investigations propose to change the chemistry concepts from abstract to concrete by practice of A.V. aids and I.T techniques in the chemistry curriculum for better scores achievement by developing interest [17], [12]. Intellectuals discovered the effects of an integrated video media curriculum enrichment on students' success as well as attitude in which interest lies [17]. According to research [6] boys' behavior about chemistry theory lessons also declined as they progressed in grade levels. Previous intellectuals such as Peter Kutnick detect that girls achieved high average scores in each subjects of Science, Mathematics, English, Social Studies etc. as compared to boys. This leading of girls remained consistent throughout the year [14], [15].

\subsection{Interest}

Interest is not an innovative concept in the field of education [2], [18], [1]. From the past century, the importance of this concept was recalled in educational world when the research verified it as a vital theme for learning and achievement in education, after recurrence of the significance of affective variables [2], [18], [1]. But the concept has critical implications in science education as the scientific literacy hold both, cognitive and affective aspects [1]. Affective domain considered as a central tendency in science education and interest is recognized as a key element in the wide scope of this domain [18]. The impression of interest seems to be confusing with many other affective variables like motivation, enjoyment and attitude [18], [1].

Interest is unique from enjoyment while learning as it's a single factor out of the huge scope of enjoyment that may be effect of many different causes like content specificity, which is a significant element of interest, discriminating it from resembling motivational concepts [1]. According to researchers, an object of interest can refer to concrete things, topic, subject-matter or abstract idea, i.e. certain part of cognitively denoted environment [2].

Aikenhead, [4] accounted a decline of interest toward school science for both, the students and stake holders. Many researches in science education pointed out a warning condition of students' declining interest in the subject of chemistry [13], [6], [12].

Students' interest towards Chemistry declined all over the world which is clear evident from previous researches [4], [13], [6], [12]. Following investigation is conducted by taking three major factors; "Parental enforcement", "Societal demands" and "Text books role". This research aimed at assessing of students' interest towards Chemistry and the exploring the factors which are responsible for this deteriorating. It will be helpful for students, parents, teachers, administrators and policy makers in recognizing and eliminating such factors which are truly liable for this frightening situation. That research is probably looked forward to the bright future of Chemistry in Pakistan. Therefore, the objectives of the study are, to:

1. Comparative Analysis between the major factors, "Parental enforcement", "Societal demands" and "Text-books role" for assessing the students" interest towards Chemistry.

2. Evaluate the influence of demographic variables (School sector, Parental occupation and Marks achievement) on major factors (Parental enforcement, Societal demands and Text books role) for measuring the students' interest towards Chemistry.

Under the light of above mentioned objectives, research questions are as follow:

1. Which major factor play its role in leading the students' interest towards Chemistry?

2. Which major factor play its role in declining the students' interest towards Chemistry?

3. What influence of demographic variables puts on major factors for students' interest towards Chemistry?

\section{Methodology}

Aim of this study signifying for quantitative approach, therefore following research falls under the causal-comparative research method. It attempts 
to determine the causes for existing variances in the individuals' performance. To measuring the prevailing interest level of students towards Chemistry, gathering the numerical data according their views on different aspects.

Population for this enquiry includes the school students from different sectors, i.e., Government, Semi-government, and Private schools at secondary level of the Lahore city, comprise of male and female students. Only the students having Chemistry subject were part of the population (excluding $\mathrm{O}$ levels Chemistry students). The stratified random sampling technique was practiced as sample type. 600 (male and female) students were part of the research sample from 9th and 10th grades. Their further categorization is given below in Figure 1.

A close ended questionnaire based on five-point Likert scale was the only instrument used to gather data from students. On experts' opinion, valid questionnaire was developed and its reliability was ensured via pilot testing. Questionnaire was divided in two major sections, i.e. demographic variables section and major factors along with their relevant statements. Demographic variables further branched into school sector, parental occupation and marks achievement of student. These branches split moreover into categories shown in Figure 2.

\section{Findings}

Major findings in the light of research questions to achieve objectives of the study, are represents in Figure 3.

According to the mean values, major factor Society requirement shows highest means value 3.60 (1.21 S.D.), itself as well as with demographic factors. Government schools (Mean= 3.64, 1.10 S.D.) from the category of school sector and Girls in the group of 71-80\% Marks Achievement shows mean value 3.86 (1.06 S.D.). From the Parental occupation, mother as working women $($ Mean $=3.73$, 1.16, S.D.) also belong to the major factor Societal demands but Fathers Occupation as Technical/ Vocational Services indicates highest 3.73 mean value (1.09 S.D.) arises only from the major factor Parental enforcement (Mean= 3.36, 1.30 S.D.).

As far as lowest mean values are concerned, mentioned at right hand side values from the figure 3. Major factor Textbooks role having 3.17 mean values (1.32 S.D.), along with all others demographical variables Govt. schools (Mean = 3.15, 1.22 S.D.) from School Sector, Teacher/ Engineer/ Doctor (Mean = 3.09, 1.41 S.D.) through Fathers Occupation, and House Wife from Mothers Occupation (Mean = 3.17, 1.33 S.D.) category. Boys also from the same major factor Role of textbook; Marks Achievement 81-90\% grouped students depicts lowest mean value as 2.95 (1.40 S.D.).

\section{Results}

The students are curious about the Chemistry. But the findings represent that the students' interest towards chemistry is not so much high. In comparison between all three factors, (Parental enforcement, Society requirements and Role of text book) the factor Role of text book designates all the declined outcomes. These results remained consistent throughout the comparison. Mean and Standard Deviation (S.D.) responses, with other demographic variables such as school sectors (Govt., Semi-govt., and Private), Parental occupation (Govt. Jobs, Private Jobs, Business, Technical Vocational Services and Teacher/ Doctor/ Engineer) by father occupations or House Wives or Working Women from the category of mother occupations, remained uniform. While, concentrated mean value is attained by the factor Society requirements and lowest by the factor Role of text book in terms of Mean and Standard Deviation which are evident what conclude earlier. In the comparison between school sectors, the government school sectors have both extremes. If it is concerned for highest mean values, same sector achieved high mean and standard deviation scores for the factor Society requirements and for lowest mean values again Govt. school sector is contributing for the factor Role of text book. From Parental occupations, in the category of Mother Occupation, the factor Society requirements is again leading with its high mean values for the Working Women, and the factor Role of text book show minimum values for the House Wives. One more thing is evidenced that students having their fathers in Technical Vocational Services indicates their more interest towards Chemistry by the factor Parental enforcement while fathers have their profession in the field of Teacher, Engineer, or Doctor, their children are least interested towards Chemistry by the factor Role of text book. In the category of scores achievement, Girls lead. In the factor Society requirements, female students having their Marks Achievement in the range of $71-80 \%$, represents the highest mean values while Boys from the factor Role of text book reveals the minimum value of mean scores in the group of $81-90 \%$ achievement scores.

In further deep analysis, after applying t-test and One-Way ANOVA to all factors one by one, from the factor Parental enforcement the Government school sectors demonstrate the significant difference with other school sectors as Semi-govt. and Private schools. Technical and Vocational Services (T/V) of father occupation illustrates significant mean difference with Govt. Jobs, Private Jobs, Business and T/E/D (Teacher/ Engineer/ Doctor) by the factor Parental enforcement. And 81- 90\% Marks Achievement scores illuminate significant mean difference with 61- 70\% Marks and 71-80\% Marks 


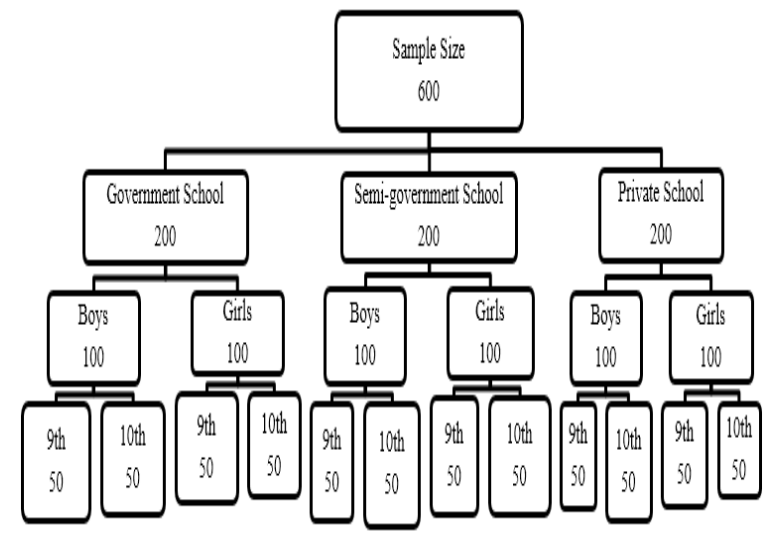

Figure. 1. Sample division

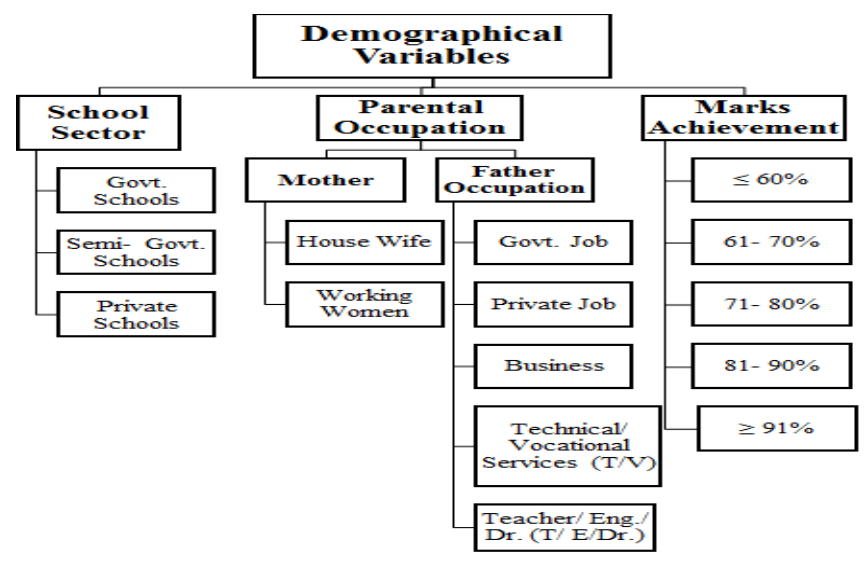

Figure 2. Demographic variables division

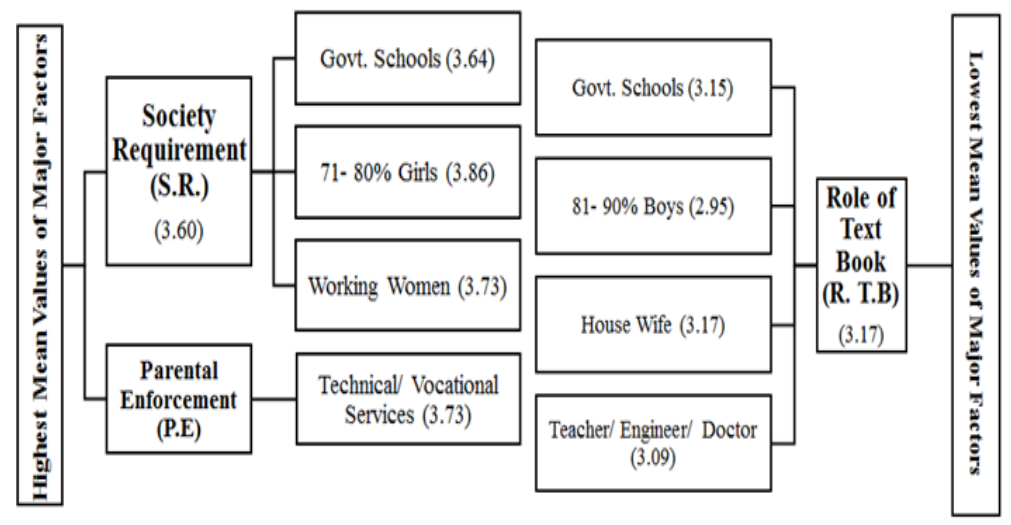

Figure 3. Findings of the research

Achievement range. From the factor Society requirements, Marks Achievement $\geq 91 \%$ with $\leq 60$ $\%$ range demonstrate significant mean difference, and from the factor Role of textbook this difference explores within the range of $\geq 91 \%$ with $81-90 \%$ Marks achievement. 


\section{Discussion}

In the science educational societies, the concept of interest has warmly discussed [2], [1]. The students convey their concerns as their secondary science starts [1]. These concerns support them in rising their interest towards the science subjects [27]. The delay or lack for acquisition the curiosity requisites to students towards the science subjects may leads to the decline in interest [10]. It is an evident that students' interest is decline in various countries throughout the globe [4], [6], [7], [8], [9], [1], [28], [11], [12], [3], [13]. The current study indicates that female students have leading interest in Chemistry than male. These findings are aligned with the research of Ogunkola and Samuel [12]. The students' interest towards Chemistry declines as a pattern of school sectors moving from Government to Semi-government schools and further towards Private school sectors. Researchers testified that school students who considered Chemistry less difficult subject those schools demonstrate better results [12]. The explanations possibly will be linked to the family income desires or the positive or negative influence of Parental Occupations. There is necessity to investigate the reasons behind these findings.

Parental enforcement is imposing a constructive effect on students' interest towards Chemistry. Scholars [29] argued that more parents influence, most the enrolment of students. The social impact is also important and helpful for development of interest towards Chemistry. Many scientists reported that the role of society is crucial for the interest construction [3]. The science not only influence the society but the society also play role in determining the students interest towards or away from science learning and understanding. The content in Chemistry books is failed to develop a true scientific attitude in students. Curriculum applications unable to modify the beliefs of students on behalf of the importance of Chemistry [6]. These results are contradictory with others [7] as indicated that students felt anxiety due to wide syllabus.

\section{Conclusion}

Among the different major factors, the Society requirements plays significant role for development of students' interest towards Chemistry subject. On other hand, the factor which is mainly responsible for declining the students' interest towards learning Chemistry is the Role of text book. Girls taking more interest in Chemistry learning as compare to boys. The Government schools produced students with dominant interest for Chemistry learning while the Private school students are least interested to learn Chemistry. Among different Father Occupations the children having their fathers committed with
Technical/Vocational Services shows most concerned to learn Chemistry. The interest of the students towards Chemistry subject is advanced and dominating who could enable to catch71- $80 \%$ Marks. However, the results are not consistent for rest of Marks Achievements.

The Suggestions and Recommendations under the study for the future perspectives are as:

1. Pakistan must make a way towards international assessments (Like PISA and TIMMS) that contains in assessing the interest construction.

2. There is an ample room for curriculum and Text Books to be updated and more appealing for students to pull theirs interest back towards Chemistry.

3. Pedagogical techniques used in schools should be accurately and appropriately according to the need of students' concept understanding i.e., application of Constructivist approaches aiding with other teaching skills.

4. There must be related seminars, debates and field trips for students' encouragement and to enrich their interest and capabilities in Chemistry, to consider it valuable subject to meet the challenges of 21 st century.

5. Aptitude tests must be conducted in educational institutions before upgrading the students in secondary classes, to assist them for selecting right subjects at right time.

\section{References}

[1] Krapp, A., and Prenzel, M. (2011). Research on Interest in Science: Theories, Methods, and Findings. International Journal of Science Education, 33(1), 27- 50.

[2] Deci, E. L., and Ryan, R. M. (2002). Handbook of SelfDetermination Research. New York: University of Rochester Press.

[3] Osborne, J., Simon, S., and Collins, S. (2003). Attitudes Towards Science: A Review of the Literature and its Implications. International Journal of Science Education, 25(9), 1049- 1079.

[4] Aikenhead, G. S. (2003). Chemistry and Physics Instruction: Integration, Ideologies, and Choices. Chemical Education: Research and Practice, 4(2), 115- 130.

[5] Government of Pakistan. (2006). National Curriculum for Chemistry at IX- X Grades. Islamabad: Ministry of Education.

[6] Cheung, D. (2009). Students' Attitudes Toward Chemistry Lessons: The Interaction Effect between Grade Level and Gender. Research in Science Education, 39(1), 75- 91.

[7] Jegede, S. A. (2007). Students' Anxiety towards the Learning of Chemistry in some Nigerian Secondary Schools. Educational Research and Reviews, 2(7), 193197. 
[8] Jones, M. G., Howe, A., and Rua, M. J. (2000). Gender Difference in Students' Experiences, Interests, and Attitudes towards Science and Scientists. Science Education, 84(2), 180- 192.

[9] Jong, O. d. (2008). Context-Based Chemical Education: How to Improve It? Chemical Education International, 8(1).

[10] Osborne, J., and Collins, S. (2000). Pupils' and Parents' Views of the School Science Curriculum. King's College London.

[11] Miller, P. H., Blessing, J. S., and Schwartz, S. (2007). Gender Differences in High- School Students' Views about Science. International Journal of Science Education, 28(4), 363- 381.

[12] Ogunkola, B. J., and Samuel, D. (2011). Science Teachers' and Students' Perceived Difficult Topics in the Integrated Science Curriculum of Lower Secondary Schools in Barbados. World Journal of Education, 1(2).

[13] Salta, K., and Tzougraki, C. (2004). Attitudes Toward Chemistry Among 11th Grade Students in High Schools in Greece. Science Education, 88(4), 535- 547.

[14] Georgiou, S. N. (1999). Parental Attributions as Predictors of Involvement and Influences on Child Achievement. British Journal of Educational Psychology, 69(3), 409- 429.

[15] Kutnick, P. (1999). Quantitative and Case- Based Insights into Issues of Gender and School- Based Achievement: Beyond Simplistic Explanations. Curriculum Journal, 10(2), 253- 282.

[16] Semela, T. (2010). Who is Joining Physics and Why? Factors Influencing the Choices of Physics among Ethiopian University Students. International Journal of Environmental and Science Education, 5(3), 319- 340.

[17] Harwood, W. S., and McMahon, M. M. (1997). Effects of Integrated Video Media on Student Achievement and Attitudes in High School Chemistry. Journal of Research in Science Teaching, 34(6), 617- 631.

[18] Hidi, S., and Renninger, K. A. (2006). The FourPhase Model of Interest Development. Educational Psychologist, 41(2), 111- 127. 